УДК 1,61

DOI: $10.18101 / 2306-1995-2019-1-62-66$

\title{
ПСИХОЛОГИЧЕСКИЕ ПОДХОДЫ К ЛЕЧЕНИЮ ПАЦИЕНТОВ СТОМАТОЛОГИЧЕСКОГО ПРОФИЛЯ: ТЕРАПЕВТИЧЕСКИЙ АЛЬЯНС И ПСИХОТИПЫ ПАЦИЕНТОВ НА АМБУЛАТОРНОМ ПРИЕМЕ
}

\author{
(C) Гуржапова Анжелика Анатольевна \\ кандидат медицинских наук, врач высшей категории, \\ ГАУЗ «Республиканская стоматологическая поликлиника» \\ Россия, 670000, Улан-Удэ, ул. Пирогова, 15а \\ E-mail: elenabotoeva@list.ru \\ Тел. 8(3012)41-66-67
}

В статье обсуждаются психотерапевтические подходы к лечению пациентов стоматологического профиля: терапевтический альянс и психотипы пациентов на амбулаторном приеме. В последние годы заметен повышенный интерес российских специалистов работающих в сфере «человек - человек» к знаниям психологии межличностной коммуникации. Сегодня многие врачи-стоматологи пытаются раскрыть сущность психологических проблем пациента и применить специальные техники индивидуального подхода при выборе способа лечения. Знание особенностей своего больного позволяет врачу вовремя сгладить конфликтную ситуацию, облегчить для пациента психотравмирующий фактор лечения и предотвратить ятрогении. Врач обязан знать особенности каждого пациента и учитывать их при разработке стратегии лечения. Это позволяет минимизировать вероятность возникновения деструктивных психосоматических состояний, которые могут навредить ходу лечебного процесса.

Ключевые слова: стоматологический прием, специалист со знанием психологии, психотипы пациентов, астеник, психастеник, шизоид, параноик, истерик, эпилептоид, тактика поведения, помощь сложным пациентам.

\section{Для цитирования:}

Гуржапова А. А. Психологические подходы к лечению пациентов стоматологического профиля: терапевтический альянс и психотипы пациентов на амбулаторном приеме // Вестник Бурятского государственного университета. Медицина и фармация. 2019. Вып. 1. С. 62-66.

\section{Введение}

При стоматологических вмешательствах врачи, зачастую ограничиваются клиническим обследованием пациентов, не уделяя должного внимания психологическим особенностям больных. Вследствие этого не используются возможности эмоциональной регуляции больных с учетом человеческой индивидуальности в целом, а от этого во многом зависит успех стоматологического лечения, так как многим пациентам важно наличие заинтересованности доктора в его проблеме.

Все контакты между стоматологами и пациентами помимо лечебной связи являются системой человеческих взаимоотношений, и от этого зависит успех оказанного лечения.

Важно добиться того, чтобы у пациентов возникло позитивное отношение к личности и лечебной деятельности врача. В противоположной ситуации в лечении могут возникать проблемы и осложнения: напряжения в общении, личност- 
A. А. Гуржапова. Психологические подходы к лечению пациентов стоматологического профиля: терапевтический альянс и психотипы пациентов на амбулаторном приеме

ный конфликт, а в конечном итоге - отказ пациента проходить лечение у такого доктора. Стоматолог должен уметь составить индивидуальный психологический портрет пациента с целью планирования и реализации дальнейшего лечения.

Необходимо помнить, что нет общей модели для определения индивидуальности, но существует типологическая оценка личности, а это уже специфическая психологическая задача для врача-стоматолога.

Типологический подход к индивидуальным особенностям пациента

Первичный инструмент для выявления психологических особенностей конкретной личности - это типологический подход. Самая известная психологическая типология базируется на таких качествах, как экстраверсия и интроверсия (Карл Юнг, 1921 год). Юнг рассматривает эти характеристики как фундаментальные альтернативные отношения, лежащие в основе человеческого опыта. Эта типология полезна для клинической стоматологической практики как первичный ориентир поведения пациента.

Для практического использования в стоматологии можно рассматривать три характеристики индивидуума: темперамент, характер и личность.

. Согласно И. П. Павлову, по своему темпераменту все люди делятся на сангвиников, холериков, флегматиков и меланхоликов. Изменить темперамент невозможно, но отчасти можно научиться его контролировать.

Следующий уровень психической организации - характер. Это совокупность психической деятельности человека: особенности восприятия, мышления, эмоций, воли и т.п. В психиатрии утвердилось мнение, что особенности характера могут быть врожденными, а могут приобретаться в раннем детском возрасте под влиянием факторов внешней среды. У большинства людей все части характера находятся в своеобразном равновесии, одно компенсирует другое, не мешая человеку развиваться, строить отношения, создавать семью, адаптироваться в социуме. Но иногда какая-то черта характера выступает более выпукло, более заметно, изменяет всю картину душевной жизни, влияет на различные стороны его деятельности. Такой человек может быть более тревожно-сомневающимся или упрямо-ригидным, более замкнутым или демонстративным. В любом случае, если он может адаптироваться в обществе, пусть иногда с некоторыми трудностями, мы говорим об акцентуациях характера.

Личность зависит от таких факторов: социальное происхождение, образование и те качества и свойства, которые были приобретены человеком течение жизни.

Типологическая оценка личности поможет врачу-стоматологу в работе, потому что нужно не только профессионально делать «лечебную» часть работы (ставить пломбы, отбеливать зубы и т. п.), но и уметь выявлять человеческий характер, поведение, чтобы строить дружественные взаимоотношения с пациентом для успешного результата лечения. Для этого необходимо знать о характеристике наиболее частых типов личности.

Астеники. Часто эти люди отличаются худощавым телосложением, длинными конечностями и шеей, узкими плечами, бледным вытянутым лицом. Они плохо переносят физическую и умственную нагрузку, быстро устают. Астеники - люди раздражительные, ранимые и обидчивые. Обиду они могут выплеснуть на окружающих, не слишком выбирая выражений, но тут же истощаются, начинают мучиться угрызениями совести за свое поведение, могут заплакать или уйти в себя. Это впечатлительные, мнительные люди, постоянно ждущие непри- 
ятностей. Они легко дают депрессивные реакции с переживаниями собственной малоценности, никчемности, ощущают себя обузой для окружающих.

Тактика поведения. От врача требуется мягкость, ободрение и поддержка, не следует быть авторитарным, давить на больного. Говорить с ним нужно тихим, спокойным, доброжелательным голосом. Хорошо включить в свою речь элементы внушения, подстраиваясь под интонации собеседника, постепенно замедляясь и понижая накал беседы. Не стоит вдаваться в научные и медицинские подробности, поскольку они могут лишь подпитать страхи пациента. Задача врача в таких случаях ободрить больного, внушить ему, что будет хорошо, что ему обязательно помогут.

Психастеники. Эти пациенты похожи на астеников, но требуют от врача совершенно иного подхода. По своему телосложению, вегетативной неустойчивости и склонности к психосоматическим заболеваниям они полностью повторяют астеников. Но в основе характера таких людей лежит не повышенная истощаемость, а изначально высокий уровень тревожности. Эти люди все время ждут неприятностей, опасностей. Они склонны к рефлексии: постоянно продумывают, проигрывают в голове те или иные события и их возможные последствия, приобретающие в их сознании катастрофический уровень. Психастеник всегда внимательно, досконально изучит аннотацию к лекарству или возможные осложнения при стоматологических манипуляциях. Естественно, именно эти осложнения у него обязательно возникнут.

Тактика поведения. Такой пациент - материалист, в основе многих его переживаний лежит страх смерти, поэтому любые болезненные и неприятные ощущения психастеник мысленно достраивает до неизлечимого заболевания. Суховатые, рациональные, рассудочные люди, они лучше всего реагируют на уверенное, компетентное поведение врача. В отличие от астеников, им требуется не эмоциональная поддержка, а рациональные научные объяснения. С таким больным лучше потратить время на доскональный разбор его тревог и сомнений, апеллируя к логике и последним научным достижениям, чем потом бороться с их ипохондрическими идеями. Держаться с таким больным нужно исключительно корректно, хорошо подойдет немного старомодная, почти утрированная вежливость.

Шизоиды. Главная черта характера - замкнутость, необщительность. Именно сниженная потребность в общении и отличает их от других типов характеров. Ему лучше всего быть одному, с любимым компьютером, книжкой и другими вещами. Шизоиду, как правило, безразличен внешний вид, поэтому он может выглядеть очень непритязательно. Кроме замкнутости они часто отличаются пониженной эмпатией, т. е. они не ощущают эмоции других людей, плохо улавливают невербальную часть общения: интонации голоса, мимику и т.п.

Тактика поведения. В общении с таким пациентом инициатива должна принадлежать врачу. Не стоит ждать, что шизоид расскажет вам все обстоятельства своей болезни, расспросите его как можно более детально. Это же касается лечения: таким людям необходимо четко и однозначно расписывать все дальнейшие шаги: когда прийти к врачу, какие манипуляции нужно делать дома и сколько раз и т.п. Желательно убедиться, что вас правильно поняли. Для этого попросите пациента повторить рекомендации.

Паранойяльные. Мир паранойяльного человека опасен и лишь от его собственной бдительности зависит его же безопасность. Все происходящие события 
A. А. Гуржапова. Психологические подходы к лечению пациентов стоматологического профиля: терапевтический альянс и психотипы пациентов на амбулаторном приеме

имеют для него особое значение, встраиваются в его концепцию мира. Подозрительные, мнительные, такие пациенты склонны к кверулянтству и сутяжничеству. Они всегда готовы подать в суд и до конца отстаивать справедливость (в их представлении). Паранойяльные люди склонны к образованию сверхценных идей - идей, возникших на реальной основе, но занявших непропорционально большое, центральное место в жизни человека. Это могут быть как религиозные или политические идеи, так и бесконечные судебные иски.

Тактика поведения. Общаясь с таким пациентом, всегда помните о возможности судебного разбирательства. Будьте сдержаны, достаточно формальны и очень профессиональны. Строго следуйте всем правилам и инструкциям, фиксируйте любую свою манипуляцию в документах, любые сложные и неоднозначные вопросы решайте коллегиально. В общении с такими пациентами помните, «все, что вы скажите, может быть использовано против вас».

Истерики. Эгоизм и эгоцентризм - вот ключевые черты характера любого истерика. Основная задача - быть в центре внимания. Для этого подходят любые способы: яркая броская одежда, эпатажное поведение, занимательные истории. На приеме у врача они ведут себя театрально, манерно, требуют к себе особого отношения, пытаются манипулировать врачом. Для истериков характерна так называемая условная желательность болезненного синдрома. Это означает, что подобный пациент умеет извлекать выгоду из своей болезни: внимание близких, поблажки на работе, подарки в утешение, группу инвалидности и т.д. Истерик может не помнить о чем-то для него неприятном и убеждать персонал, что ему об этом ничего не известно.

Тактика поведения. Прежде всего сохраняйте спокойствие: не подпитывайте эмоции пациента. Врач должен держаться несколько отстраненно, четко соблюдать дистанцию, контролировать беседу, не давая ей превратиться в монолог пациента. Не следует поддаваться на попытки манипуляций, провокаций и откровенно шантажное поведение больного. Избегайте гипердиагностики соматоформных расстройств, помните, что истерия может имитировать практически любое заболевание. В любых сомнительных ситуациях прибегайте к коллегиальным решениям.

Эпилептоиды. Люди обстоятельные, неторопливые и ригидные. У них однозначная жизненная позиция и правила поведения, не допускающие никаких отклонений.

Тактика поведения. Следует запастись терпением и внимательно выслушивать его крайне подробные и обстоятельные жалобы. Работая с пациентомэпилептоидом, врач должен вести себя профессионально, вежливо, соблюдать все социальные ритуалы (поздороваться, пожать руку и т.п.). Не стоит шутить чувство юмора у эпилептоидов, как правило, отсутствует, и шутливые высказывания могут быть восприняты в лучшем случае как несерьезность врача, а в худшем - как издевательство. Эпилептоиды склонны к приступам тоскливозлобного настроения с чувством зависти и ненависти к здоровым людям, а также к вспышкам гнева, во время которых они плохо контролируют свое поведение. Поэтому следует внимательно отслеживать состояние такого пациента и не давать ему «закипать», переключая тему беседы на текущие дела.

\section{Заключение}

Все вышеописанные и многие другие типы характеров определяют реакцию пациента на соматическое страдание. Так, психастеники и астеники склонны пе- 
реоценивать тяжесть своего состояния, шизоиды - напротив, недооценивают ситуацию. Истерики аггравируют (утяжеляют) болезнь и т. д. К тому же заострение характерологических черт делает человека более уязвимым к стрессовым факторам, предрасполагает его к развитию психогенных заболеваний и к своим, свойственным каждому типу, вариантам конфликтного поведения в кабинете врача.

Знание особенностей своего больного позволяет врачу вовремя сгладить конфликтную ситуацию, облегчить для пациента психотравмирующий фактор лечения и предотвратить ятрогении. Душевное равновесие, уверенность в себе, в своих силах, знаниях и возможностях и, конечно, поддержка коллег позволят успешно помочь любым, даже самым сложным пациентам.

Литература

1. Бурно М. Е. Клиническая психотерапия. М.: Академический проект, ОПП, 2000. $719 \mathrm{c}$.

2. Леонтьев В. К. Этические принципы и кодекс профессионального поведения стоматолога // Стоматология для всех. 1998. № 1. С. 52-54.

3. Гольдштейн Р. Эстетическая стоматология. Т. 2 // Русское издание; под ред. А. М. Соловьевой. Канада, 2003. 493 с.

\section{PSYCHOLOGICAL APPROACHES \\ TO THE TREATMENT OF DENTAL PATIENTS: \\ THERAPEUTIC ALLIANCE AND PSYCHOTYPES OF OUTPATIENTS}

Anzhelika A. Gurzhapova

Candidate of Medical Sciences, Board Certified in Dentistry, Republican Dental Clinic

15a, Pirogov str., Ulan-Ude, 670000 Russia

E-mail: elenabotoeva@list.ru

Tel.: +73012416667

Psychotherapeutic approaches to the treatment of dental patients studies therapeutic alliance and psychotypes of outpatients. All doctors repeatedly deal with difficult patients who are demonstrative and intrusive, anxious and sensitive, assertive and impudent, thorough and taciturn, demanding and completely indifferent and finally, just weird, requiring obviously unnecessary treatment and expensive prosthetics. Lately Russian professionals working in the field of interpersonal relationships are getting more interested in interpersonal communication psychology. Today many dentists are trying to reveal the essence of the patient's psychological problems and work individually while choosing treatment methods. Knowing the characteristics of a patient allows the doctor timely smooth out the controversy, facilitate psycho-traumatic factor of treatment and prevent iatrogenesis. The doctor must know the characteristics of each patient and take them into account when developing a treatment strategy. This will minimize the destructive psychosomatic conditions that can disrupt the treatment process.

Keyword: dental reception, specialist with knowledge of Psychology, psychotypes of patients, asthenic, psychasthenic, schizoid, paranoid, hysterical, epileptoid, treating approach, assistance to difficult patients. 